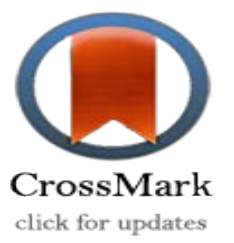

\title{
Elderly perceived stress: the predictive role of spiritual well-being, coping
}

\author{
strategies, and sense of cohesion \\ *Eyni $\mathrm{S}^{1}$, Hashemi Z², Tagavi R ${ }^{3}$
}

1- PhD of psychology., Department of Psychology, Faculty of Educational Sciences and Psychology, University of Mohaghegh Ardabili, Ardebil, Iran (Corresponding Author)

Email: sanaz.einy@yahoo.com

2- Assistant Professor of Psychology, Faculty of Humanities, University of Maragheh, East Azarbaijan, Iran.

3- MA of Clinical Psychology, Islamic Azad University, Ardabil Branch, Ardabil, Iran

\section{Abstract}

Introduction: Mental and health-related stressors are exacerbated with age. Therefore, the purpose of the present study was to investigate the role of spiritual well-being, coping strategies, and sense of cohesion in predicting perceived stress in the elderly.

Method: The research method was analytical and correlational. The statistical population of this study was all the elderly in elderly home of Mandegaran and Ata in Ardabil city in 2018 , out of whom 120 were selected by purposeful sampling based on entry criteria. Data collection tools included perceived stress scale, spiritual well-being questionnaire, coping strategies questionnaire, and 13-item cohesion sense questionnaire. Data analysis was performed using Pearson correlation coefficient and multiple linear regression.

Results: There was a negative and significant relationship between the perceived stress of elderly with spiritual well-being $(\beta=-0 / 110$ : $\mathrm{P}<0 / 004)$, problem-based coping strategy $(\beta=-0 / 152$ : $\mathrm{P}<0 / 001)$, sense of cohesion $(\beta=-0 / 176: \mathrm{P}<0 / 008)$ and positive and significant relationship with negative religious coping $(\beta=0 / 131$ : $\mathrm{P}<0 / 017)$. Spiritual well-being, coping strategies, and sense of cohesion predicted $68 \%$ of the variance in perceived stress scores of elderly $(\mathrm{P}<0 / 01)$.

Conclusion: According to the findings, spiritual well-being, coping strategies, and sense of cohesion are associated with the perceived stress of elderly and can explain how the elderly behave. Therefore, educating elderly to empower them in these areas is recommended.

Keywords: Spiritual Well-being, Coping Strategies, Sense of Cohesion, Perceived Stress, Aged.

Received: 15 November 2019 Accepted: 21 December 2019 
استرس ادر اك شده سالمندان: نقش بيش بين بهزيستى معنوى، راهبر دهاى مقابله اى و حس

\author{
انسجام

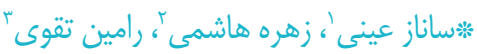

ا- دكتراى روانشناسى تخصصى، دانشكده علوم تربيتى و روانشناسى، دانشكاه محقق اردبيلى، اردبيل، ايران (نويسنده مسئول)

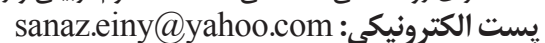

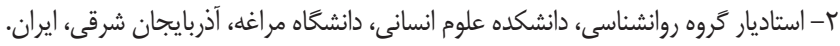

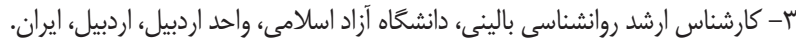

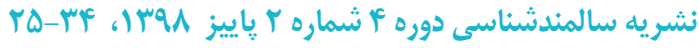

مقدمه: عوامل استرس زاى روانى و مرتبط با سلامت با افزايش سن تشديد مى شوند. از اين رو، هدف يزوهش حاضر تعيين نقش بهزيستى معنوى، راهبردهاى مقابله اى و حس انسجام در بيش بينى استرس ادراك شده سى سالمندان بود.

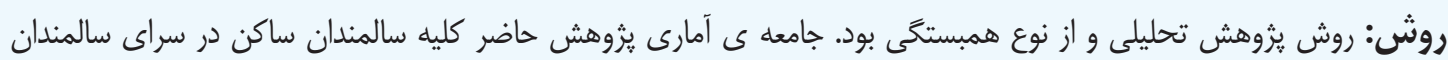

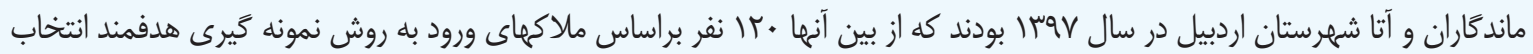

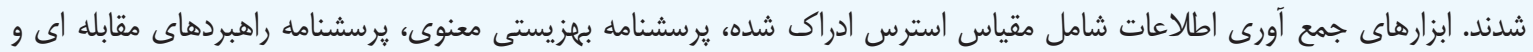

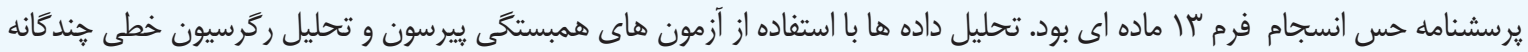
انجام شد.

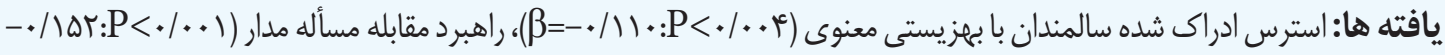
(

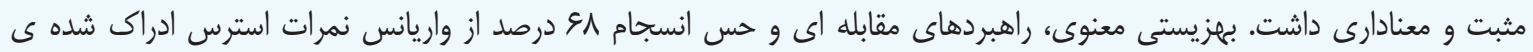

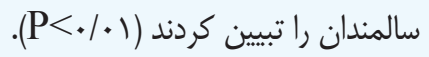
نتيجه تَيرى: براساس يافته ها، بهزيستى معنوى، راهبردهاى مقابله اى و حس انسجام با استرس ادراك شده رابطه داشته و مى

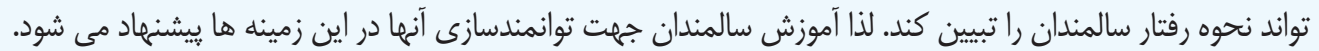
كليد وازه ها: بهزيستى معنوى، راهبردهاى مقابله، حس انسجام، استرس ادراك شده، سالمندا. تاريخ دريافت:

شيوع استرس ادراك شده در بزركسالان بالاى 9ه سال، محدود

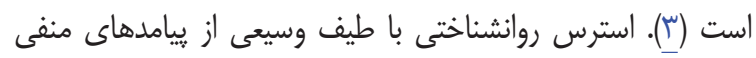

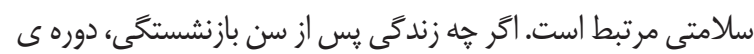

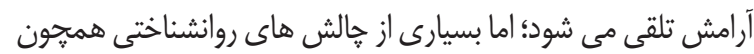

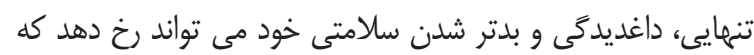

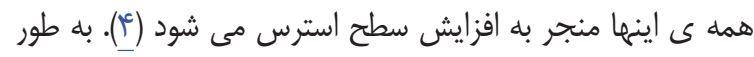
كلى، نتايج يزوهش ها نشان مى دهد كه عوامل استرس زاى مرتبط با سلامت با افزايش سن افزايش ييدا مى كند (ه). استرس بالاو و ومان پإيدار در دوران سالمندى مى تواند باعث تسريع در كاهش حافظه

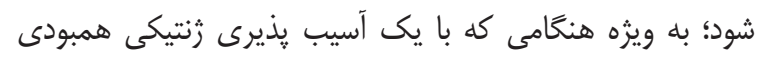
داشته ياشد (و)، خطر تبديل اختلالات خفيف شناختى به زوال عقل هيل

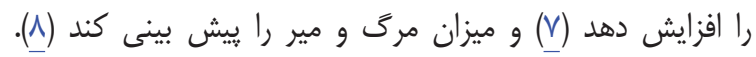

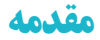

در طى خند دها ى كَذشته، اميد به زندكى به طور قابل ملاحظه اى در سراسر جهان افزايش يافته است كه اين مسأله باعث

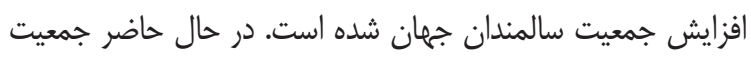
بالاى •و سال جهان حدود سا درصد مى باشد و اين نسبت به به داله

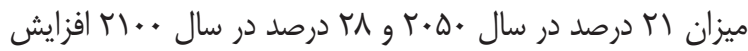

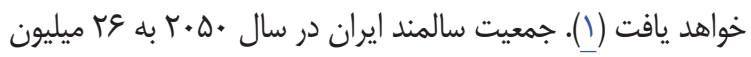

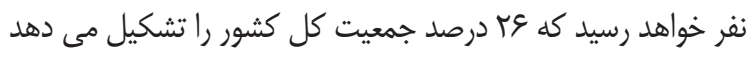

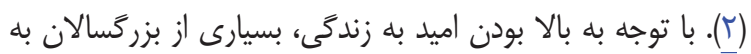

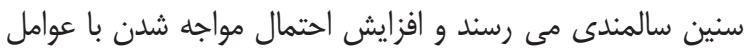

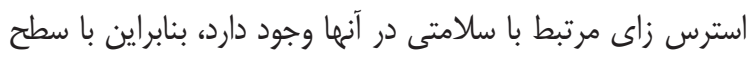
بالاى استرس ادراك شده مواجه مى شوند. شواهد در مورد ميزان 
موقعيت هاى تنش زا، كاهش تنش و نهايتاً در سلامت روان و بهزيستى روانشناختى و جسمى افراد ايفا مى كنند كه در نتيجه كنار آمدن كار آمد و بهينه با مشكلات كه يكى از نشانه هاى بهزئس يستى

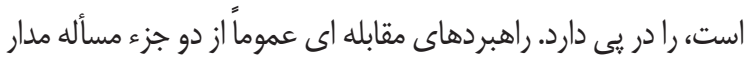
و هيجان مدار تشكيل مى شوند. در مقابله مسأله مدار فرد متمركز بر عامل استرس زا مى شود و تلاش مى كند كام هاى سازنده اي مانى براى تغيير يا حذف شرايط استرس زا انجام دهد. در مقابل در مقابله

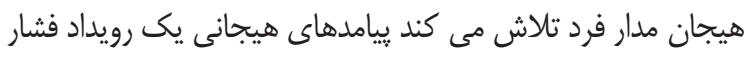

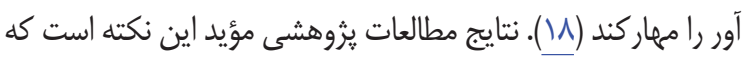
در سالمندان بيشترين عامل استرس زا، بُعد آشيانه خالى و بيشترين

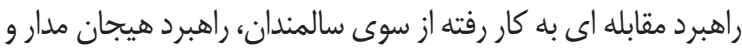

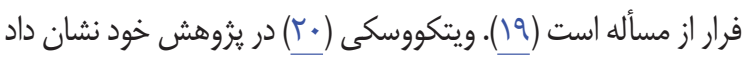
كه بين راهبردهاى مقابله اجتنابى و هيجان مدار با نكرش به مركى رابطه معنادارى وجود دارد. نتايج يزوهشى هاشمى رزينى، با حشمت

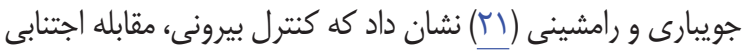

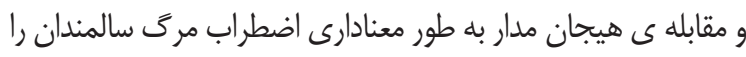

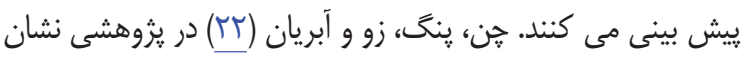

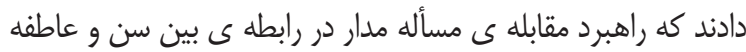
مثبت نقش ميانجى دارد؛ بنابر اين بايستى ترويج راهبرد مقابله مسأله مدار داله مدار در افراد سالمند مورد توجه قرار بحيرد.

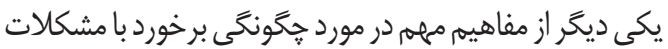
و تنش هاى ناشى از سالمندى، حس انسجام است. آنتونوسكى (بَّ) حس انسجام را يك جهت گيرى شخصى به زندگى تعريف مي كند؛

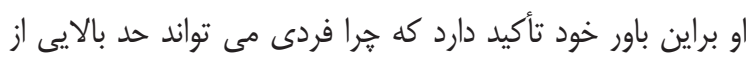
استرس را از سر بخذراند و سالم بماند. بنابراين به اعتقاد او، حس

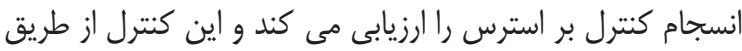

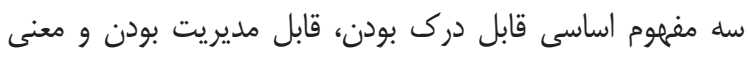

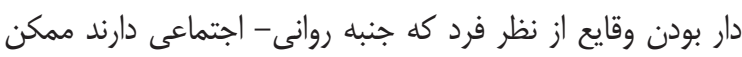
مى شود. حس انسجام عامل مهمى در يبش بينى كيفيت زندگى سالمندان است (بَ)؛؛ حس انسجام با ميانجى گَرى ترس از مركى

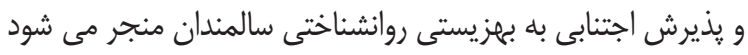
(Tه) و حس انسجام قوى با بهزيستى روانشناختى بيشتر در سالمندان همراه است (عץ). حس انسجام سالمندان با وضعيت عملكردى،

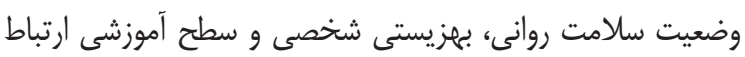

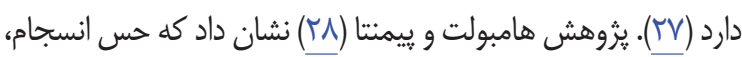
سلامت ادراك شده و سبك زندكى، بهزيستى ذهنى سالمندان رامنا ييش بينى مى كنند. بوكستنز، وايس، ساتر، آجولد، يوتلبرك، ماتى و همكاران (qَ) در يزوهشى نشان دادند كه حتى در افراد بسيار

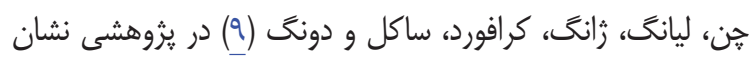
دادند كه سطح بالاى استرس ادراك شده با سطوح يايين تر عملكرد

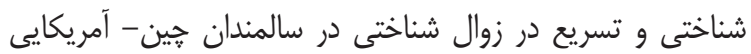

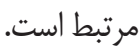
از آنجا كه استرس در نتيجه ارزيابى شناختى فرد از موقعيت

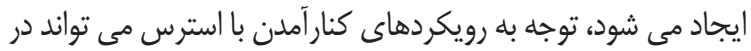
تعديل الحوهاى رفتارى و فكرى سالمندان تأثير كذار باشد. مطالعات

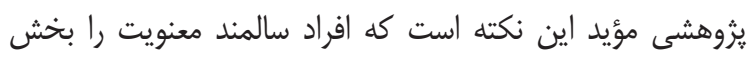

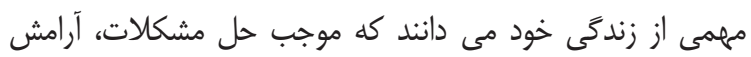

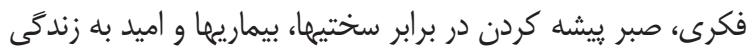
مى شود (•). يكى از مفاهيمى كه در نتيجه ى توجه يزورهشكران به حيطه معنويت مطرح كرديده، مفهوم بهزيستى معنوى است.

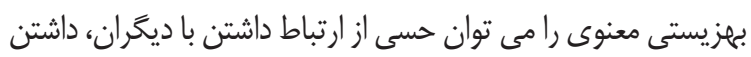

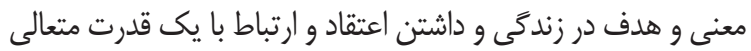

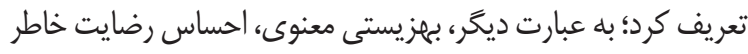

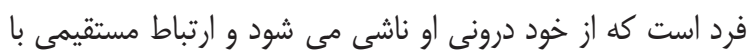
كيفيت زندگى افراد دارد. بهزيستى معنوى دو مؤلفه دارد، بهزيستى إنى مذهبى و بهزيستى وجودى . بهزيستى مذهبى به رضايت از داشتن

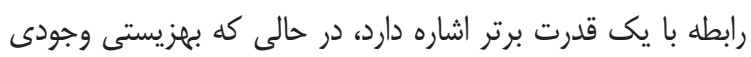

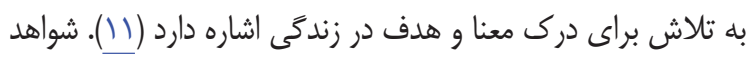
نشان مى دهد كه افراد سالخورده با باورهاى مذهبى قوى تر نسبت به ساير سالمندان، از وضعيت سلامتى بهترى برخوردار هستند؛

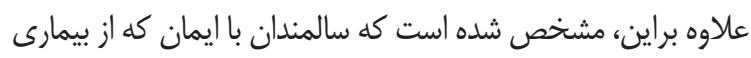

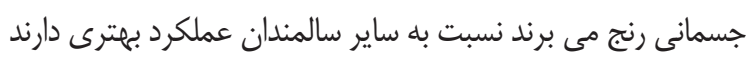
و نتايج درمانى بهترى را كسب مى كنند (T). نتايج مطالعات نشان داده است كه بين بهزيستى معنوى و كيفيت زندكى سالمندان (بآي عا1)؛ بهزيستى مذهبى، وجودى و مقابله مذهبى با اضطراب مركى

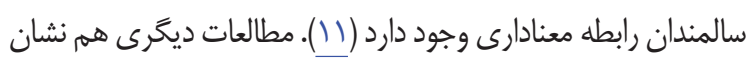
داده اند كه رابطه ى معنادارى بين معنويت، ديندارى و سلامت

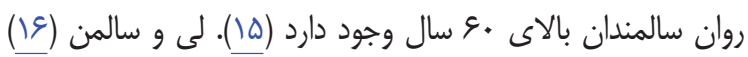

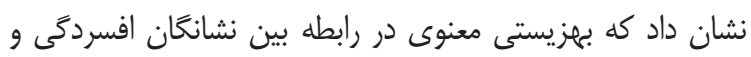
كيفيت زندگى مرتبط با سلامتى در سالمندان، نقش تعديل كنتنده دارد. همجِنين در يزوهشى ديكًر نيز نشان دادند كه بهزيستى معنوى

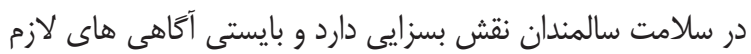

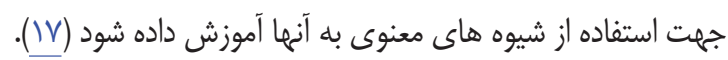
متغير ديخرى كه مى تواند در رابطه با استرس ادراك شده سالمندان مورد توجه قرار دارد، راهبردهاى مقابله اي است. براساس نظريات روان شناختى، راهبردهاى مقابله اي نقش مهمى در مديريت 
كوهن، كامارك و مارملشتاين در سال سبه19 به منظور آَاهى از اين

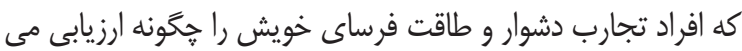
كنند، توسعه يافت. در اين مقياس از افراد تقاضا مى شود كه بر روى يك طيف ينج درجه اي از صفر (هركز) تا أ (هميشه) مشخص كنند كه اغلب در طول •( هفته كذشته خه احساسى داشته اند. در اين

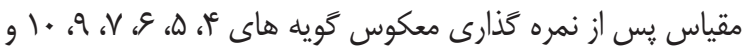
"ا، از تجميع نمره ى تمامى گويه ها براى هر فرد، نمره كلى بدست

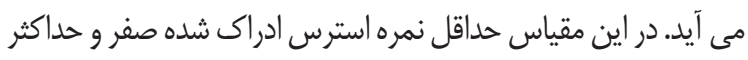
آن وه است. كسب نمره بالاتر به معنى استرس ادراك شده بيشتر

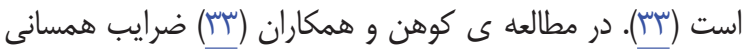

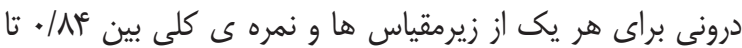

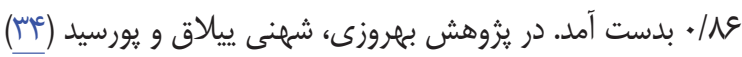
براى محاسبه يايايى استرس ادراك شده از ضريب آلفاى كرونباخ و

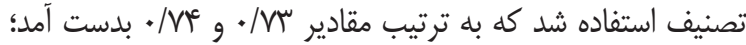

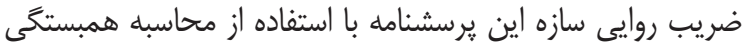
ساده با يك سؤال ملاكى محقق ساخته سواء • بدست آمد.

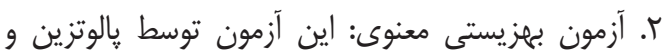

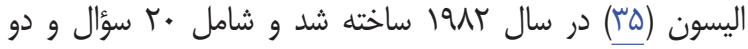
خرده مقياس است كه • ا سؤال آن بجزيستى مذهبى و • ا سؤال

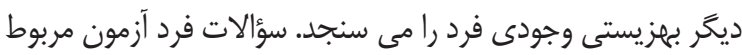
به خرده مقياس بهزيستى مذهبى بوده و ميزان تجربه فرد از رابطه

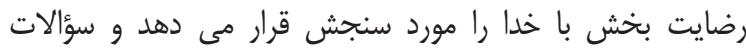
زوج مربوط به خرده مقياس بهزيستى وجودى است كه احساس هدفمندى و رضايت از زندگى رامى سنجد مقياس ياسخ اين سؤالات به صورت ليكرت 9 گز ينه اى از كاملاً مخالفم تا كاملا موافقم دسته

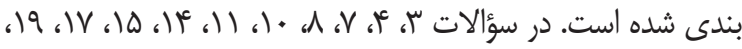

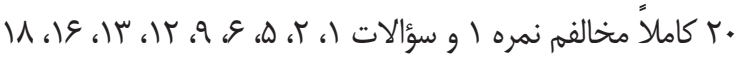

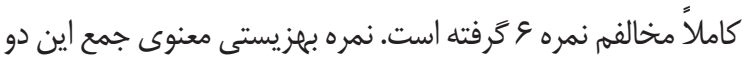

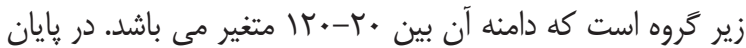

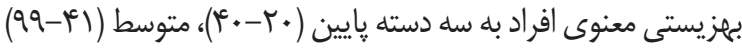

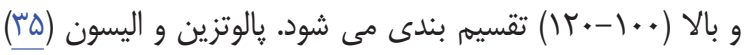

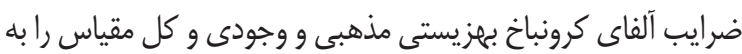

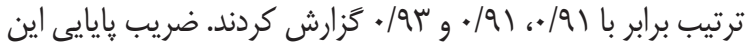
يرسشنامه در مطالعه حاضر براساس تتاى ترتيبى براى زيرمقياس ها

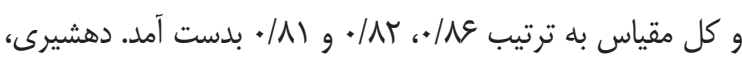
نجفى، سهرابى و ترقى جاه (عَ) در يزوهشى نشان دادند كه روايى

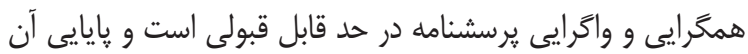

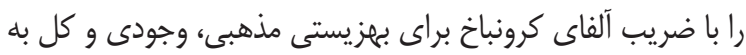

مسن حس انسجام بالا با ميزان مركَ و مير كمتر و افت عملكردى

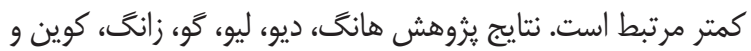

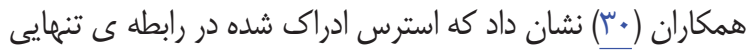

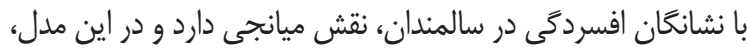
حس انسجام مى تواند به عنوان يك متغير تعديل كر عمل كند.

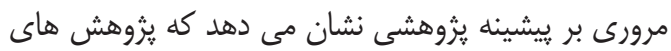

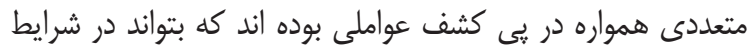

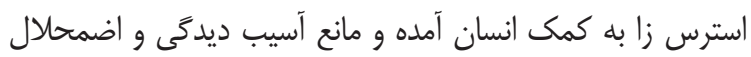
وى در زير فشار سنخَين مسائل و مشكلات زندكى شود. عوامل استرس زاى مرتبط با سلامت با افزايش سن افزايش ييدا مى كند

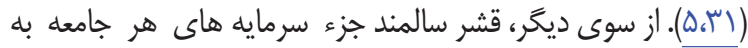

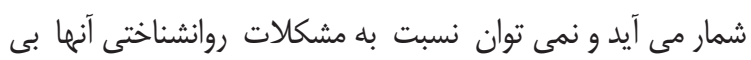

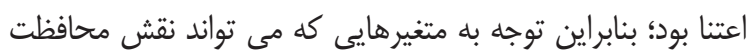
كننده در برابر استرس داشته باشد و فقدان منابع علمى كافى در مورد متغيرهاى محافظت كننده در برابر استرس در سالمندان، خلاء اى

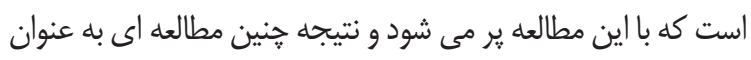
مبناى مقدماتى براى بررسى هاى بيشتر و نيز طراحى مداخلات متناسب جهت بهبود مشكلات روانشناختى سالمندان خواهد بود. از اين رو يزوهش حاضر با هدف تعيين نقش بهزيستى معنوى، راهبردهاى مقابله اى و حس انسجام در ييش بينى استرس ادراى

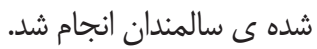

\section{روش مطالعها.}

روش يزوهش حاضر توصيفى و از نوع همبستكى است. جامعه آمارى يروهش حاضر را كليه سالمندان ساكن سراى سالمندان

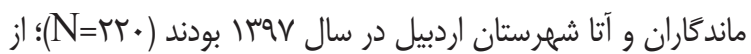

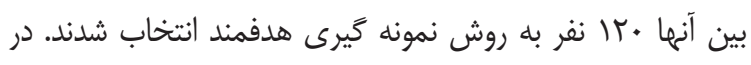

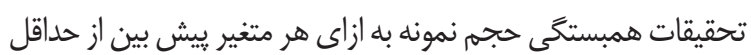

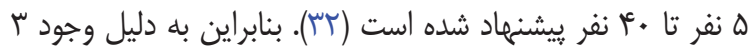
متغير ييش بين و افزايش اعتبار بيرونى، به ازاى هر متغير • +ع نفر در

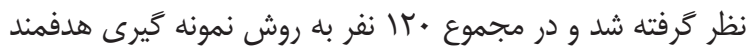

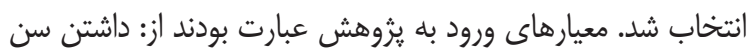
بيش از •و سال، توانايى تكميل يرسشنامه ها و ميزان تحصيلات

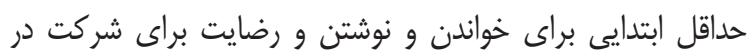
يزوهش؛ ملاك خروج هم عدم تمايل به همكارى با تيزوهشكر بود. جهت جمع آورى داده ها از ابزارهاى ذيل استفاده شد: 1. مقياس استرس ادراك شده (PSS): اين مقياس به مثابه يك ابزار خودكزارش دهى مشتمل بر عاس كويه است كه به وسيله 
جمع آورى اطلاعات، به صورت انفرادى نمونهى مورد نظر با دريافت

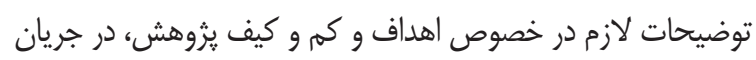

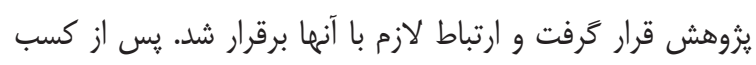

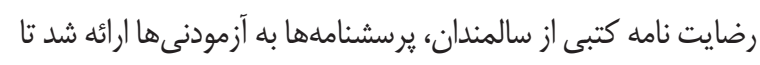

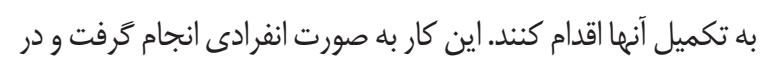

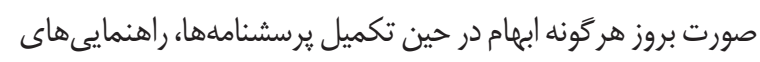

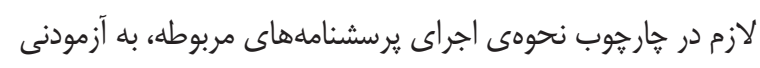

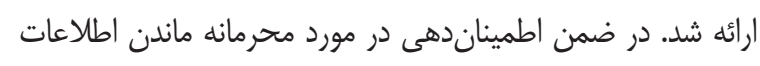

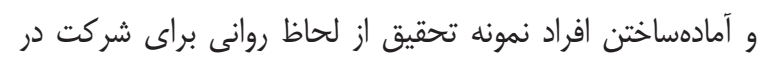

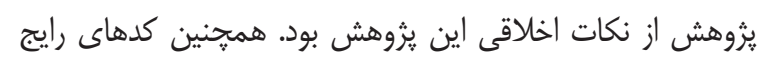

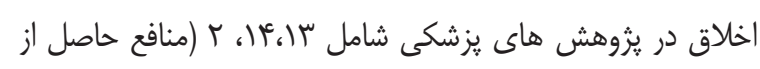

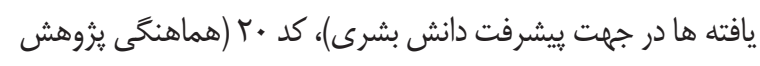

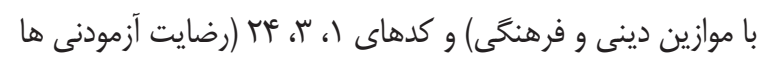
و نماينده قانونى او) در اين يُوهش رونى رعايت شده است.

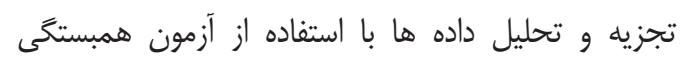

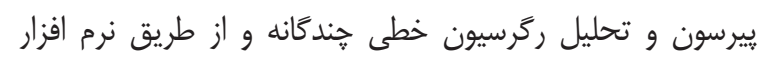

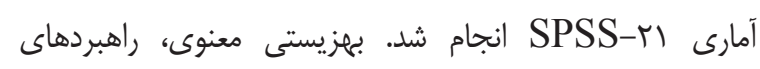

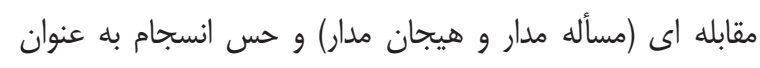

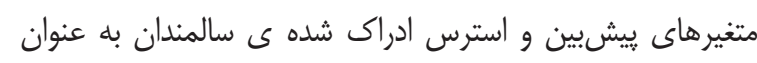
متغير ملاكى در نظر گرفته شدند.

\section{يأْته ها}

نمونه آمارى مورد مطالعه شامل • با نفر سالمند با متوسط سن سه/ \pm د

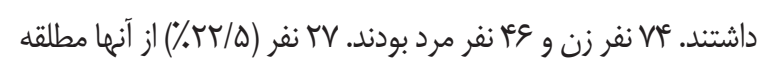

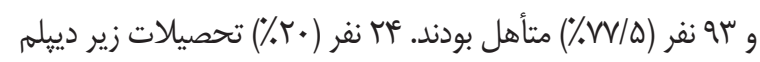

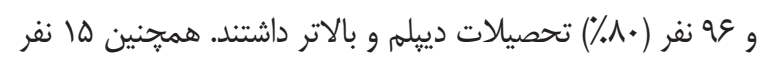

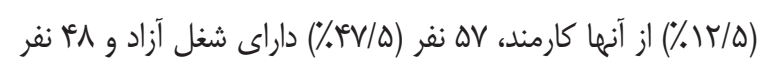

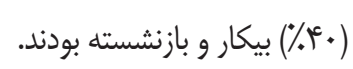

مقدار حولكى مشاهده شده براى متغيرها در بازه (ז، ؟ ب-) قرار دارد؛ يعنى از لحاظ كجى متغيرها نرمال بوده و توزيع آنها متقارن

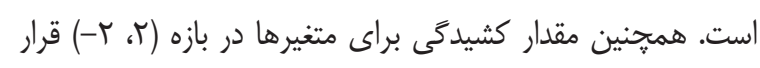

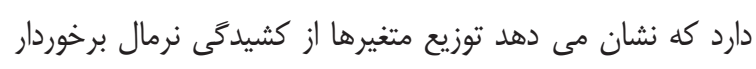

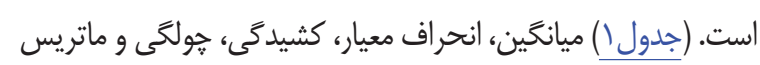
همبستخى متغير هاى يزوهش را نشان مى دهد.

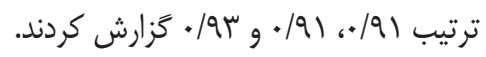

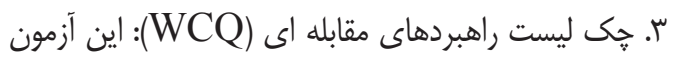
در سال ه19 اتوسط لازاروس و فولكمن ساخته شده است و مشتمل رئل

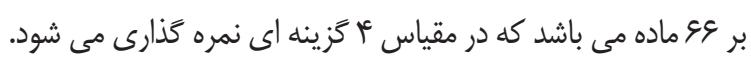
اين آزمون هشت شيوه ى مقابله اى را كه به دو دسته ى مسأله مدار و هيجان مدار تقسيم مى شوند، مورد سنجش قرار مى ملى دهد.

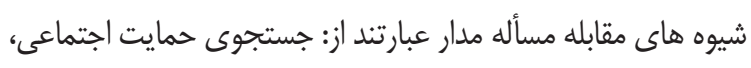

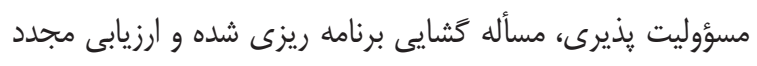

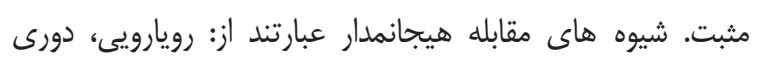

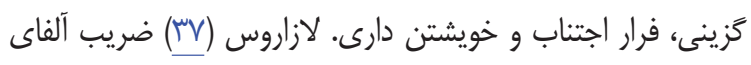

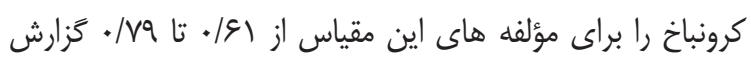

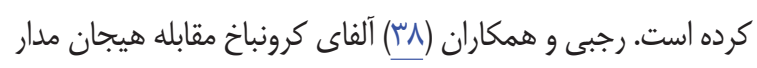

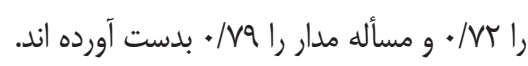
f. برسشنامه حس انسجام فرم سا ماده ایى: فرم كوتاه

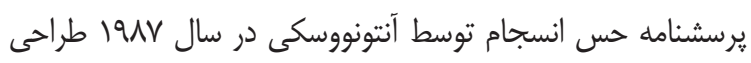

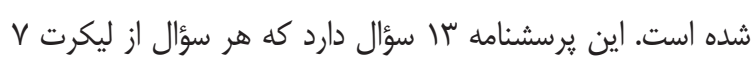

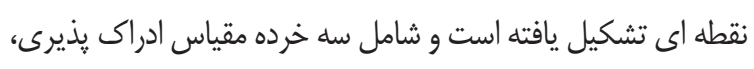

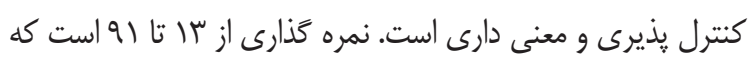

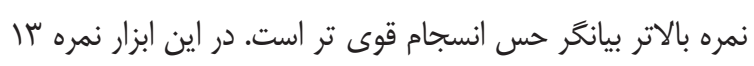

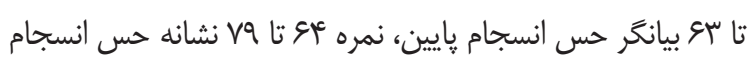

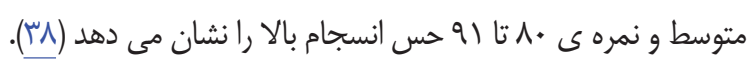

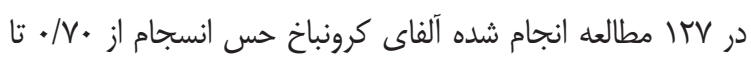

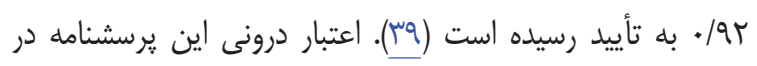

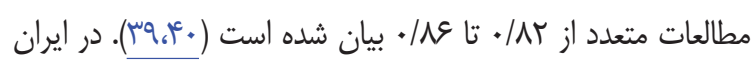

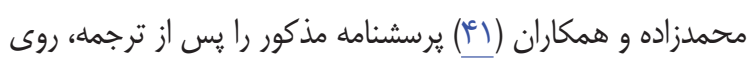

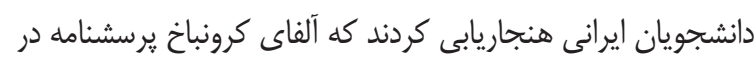

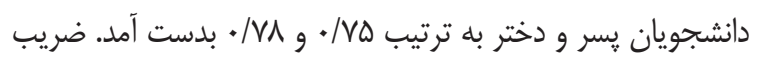

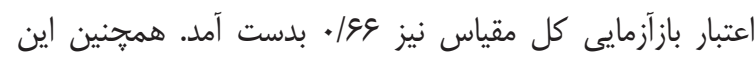

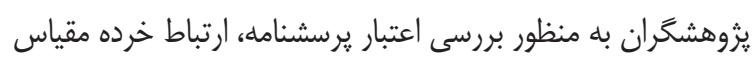

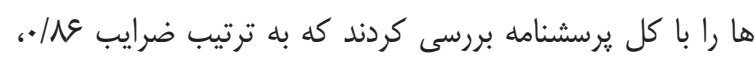

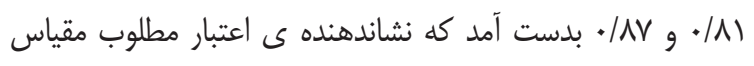

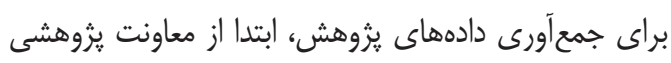

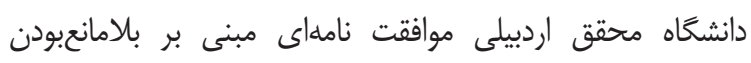

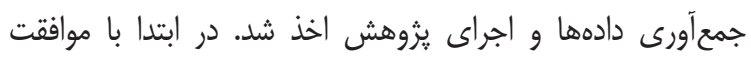

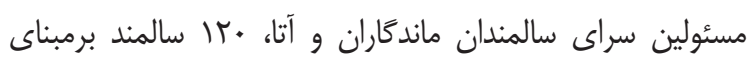

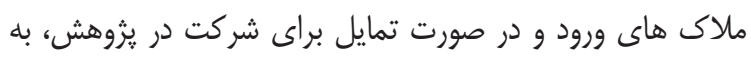

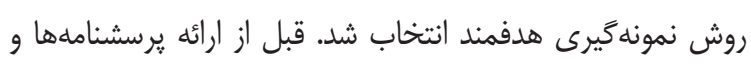


جدول (: ميانگين آمارى نمرات و ماتريس همبستخى بهزيستى معنوى، راهبردهاى مقابله (مسأله مدار؛ هيجان مدار)،حس انسجام و استرس ادراك شده س سالمندان

\begin{tabular}{|c|c|c|c|c|c|c|c|c|}
\hline$\Delta$ & f & r & r & 1 & جولنَى & كشيدگى & انحراف معيار土 ميانكَين & متغيرها \\
\hline 1 & $\begin{array}{c}1 \\
* *-/ V 1\end{array}$ & $\begin{array}{c}1 \\
*-/ / 9 \\
* * / M F\end{array}$ & $\begin{array}{c}1 \\
*-\cdot / 4 r \\
* * / \mu r \\
* *-\cdot / g r\end{array}$ & $\begin{array}{c}1 \\
* \cdot / \Delta r \\
* *-\cdot / T Y \\
* * / \Delta r \\
* *-\cdot \Delta \Lambda\end{array}$ & 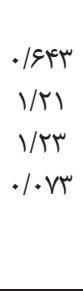 & $\begin{array}{l}\text {. /QTA } \\
\text {. IGFA } \\
. / M F A \\
. / F A T\end{array}$ & 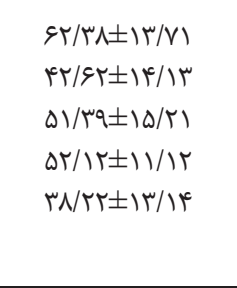 & 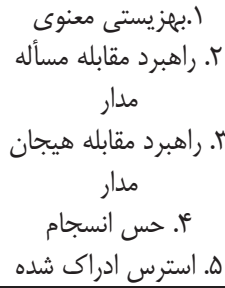 \\
\hline
\end{tabular}

مفروضه هاى رَرسيون اجرا شد. مقادير بدست آمده براى تحمل و تورم واريانس حاكى از آن بود كه مفروضه هم خطى بودن، تخطى

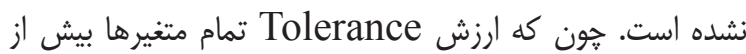

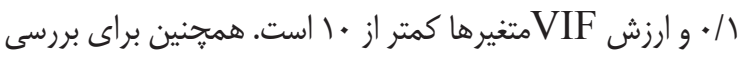

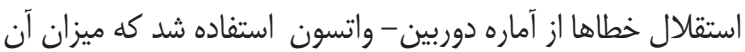
1/1/ بود كه نشان از مستقل بودن خطاها بود.

استرس ادراى شده سالمندان با بهزيستى معنوى، راهبرد مقابله مسأله مدار و حس انسجام رابطه منفى و معنادار و با راهبرد

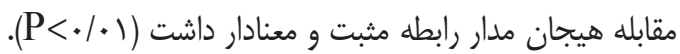
جهت تبيين سهرم بهزيستى معنوى، راهبردهاى مقابله ایى و حس انسجام در ييش بينى استرس ادراك شده سالمندان از تحليل رَرَسيون همزمان استفاده شد كه نتايج آن در ادامه آمده است. قبل از اجراى تحليل رگرسيون، يك تحليل اوليه براى بررسى لهى جدول ז: نتايج تحليل ركرّيون استرس ادراك شده سالمندان براساس بهزيستى معنوى، راهبردهاى مقابله ایى و حس انسجام

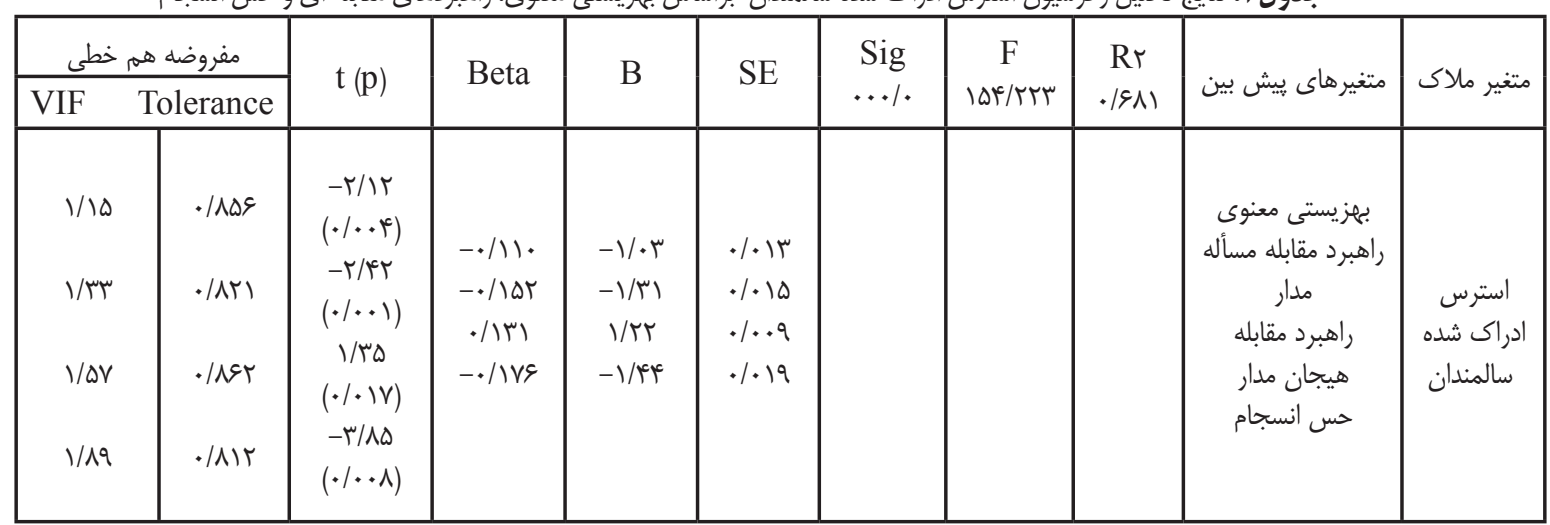

بحث

يزوهش حاضر با هدف بررسى نقش بهزيستى معنوى،

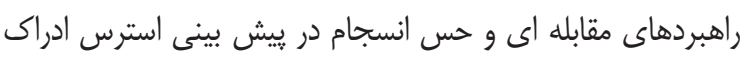
شده س سالمندان انجام شد.

نتايج ضرايب همبستخى نشان داد استرس ادراك شده ى

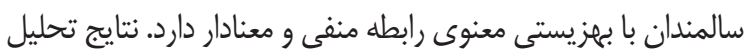

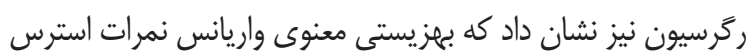
ادراك شده سالمندان را تبيين مى كند. بنابراين يافتهها از وجود ارتباط بين بهزيستى معنوى و استرس ادراك شده سالمندان حمايت

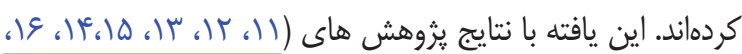

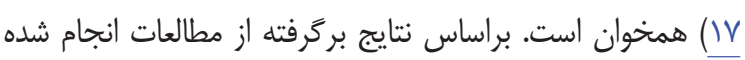

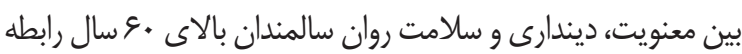
معنادارى وجود دارد (ه|). مطالعه لى و سالمن (ع|) نشان داد كه
براساس نتايج (جدول r) نتايج تحليل رگرسيون خندگانه در يبش بينى استرس ادراك شده از روى بهزيستى معنوى، راهبردهاى مقابله اى و حس انسجام، ملاحظه مى شود كه متغيرهاى ييش بين

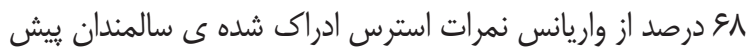

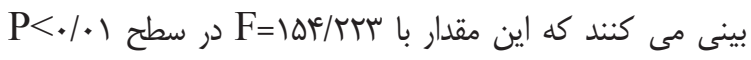
معنى دار است. نتايج ضرايب رگرسيون هم نشان مى دهد كه

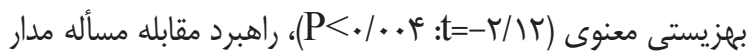

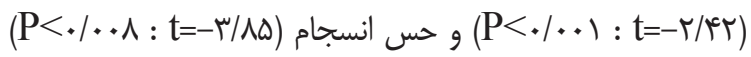

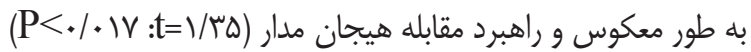
به طور مستقيم استرس ادراك شده ى سالمندان را ييش بينى مى كنند. مقادير بتا نشان داد كه حس انسجام بيشترين سهرم و

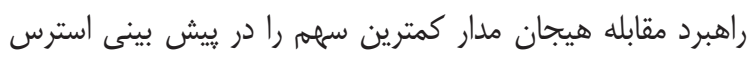
ادراك شده سالمندان دارد. 
به مرك رابطه معنادارى وجود دارد. نتايج يزوهشى هاشمى رزينى و همكاران (آr) نشان داد كه كنترل بيرونى، مقابله اجتنابى و مقابله

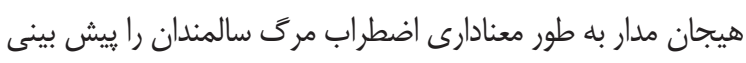

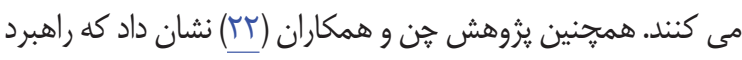
مقابله مسأله مدار در رابطه بين سن و عاطفه مثبت نقش ميانجى دارد؛ بنابراين بايستى ترويج راهبرد مقابله مسأله مدار در افراد سالمند

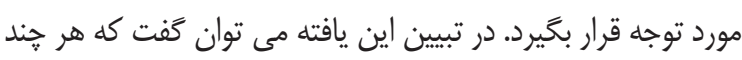

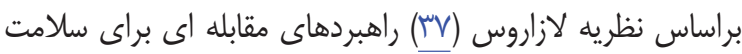

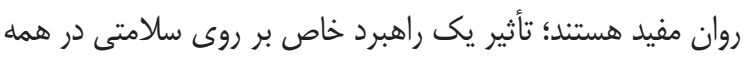
شرايط يكسان نيست. راهبردهاى مقابله اى هيجان مدار باعث

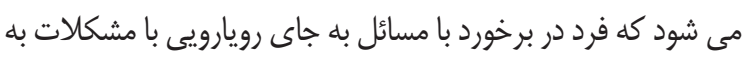
ابزارهاى ديخرى همجيون عصبانت متوسل شود ودر نتيجه ياد خواهد كرفت كه هر بار با مشكلى مواجه شود، از اين ابزار استفاده كند.

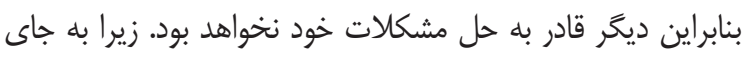

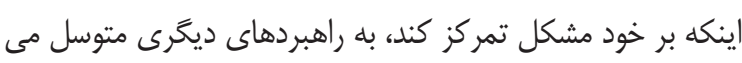

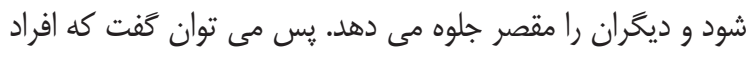

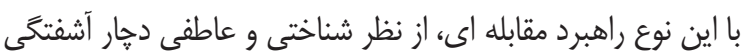

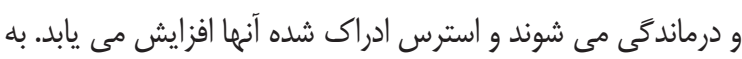

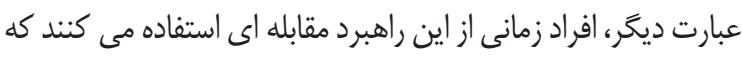

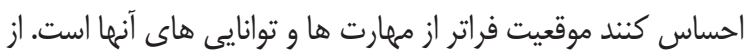

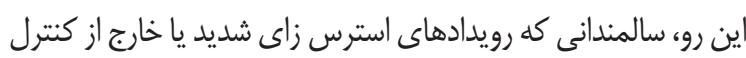

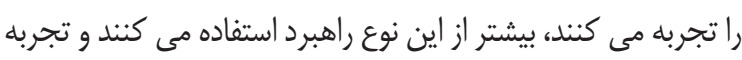
مكرر شرايط استرس زاو واستفاده مكرر از راهبرد مقابله هيجان مدار، بهزيستى روانشناختى آنها را به خطر مي اسنغاده مكرر اندازد.

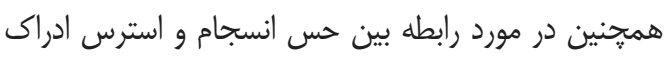

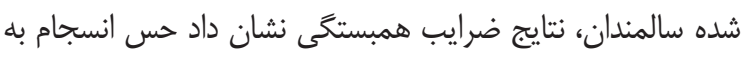
طور منفى با استرس ادراك شده سالمندان مرتبط است. نتايج تحليل ركرسيون نيز نشان داد كه نمرات حس انسجام واريانس استرس آسرات

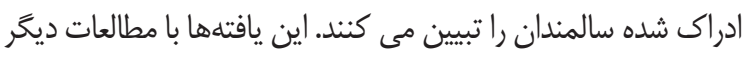

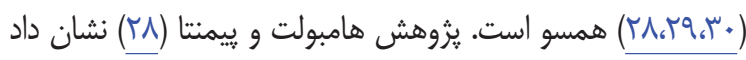

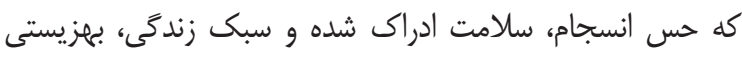

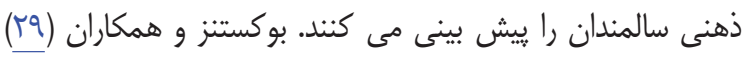

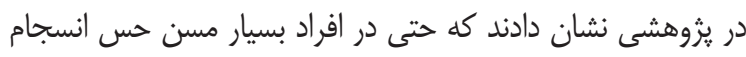
بالا با ميزان مرك و مير كمتر و افت عملكردى كمتر مرتبط است است.

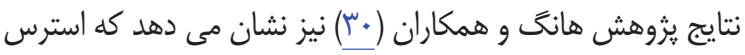

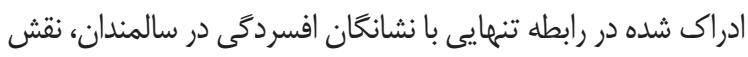

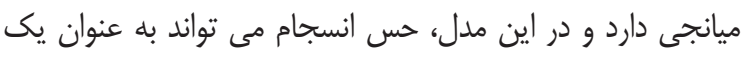
متغير تعديل كر عمل كند. در تبيين اين يافته مى توان كَفت كه ائه
بهزيستى معنوى در رابطه بين نشانكان افسردگى و كيفيت زندگى مرتبط با سلامتى در سالمندان، نقش تعديل كننده دارد. همجنين

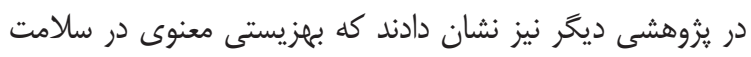

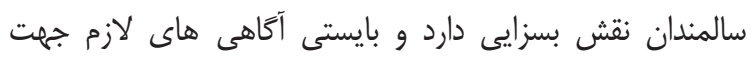

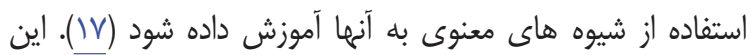

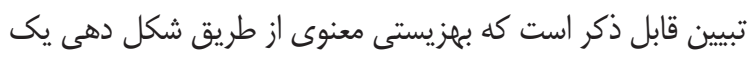

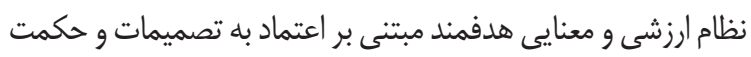
خدا (به عنوان داناى مطلق)، نوعى مقابله ى معنوى /مذهبى به راه

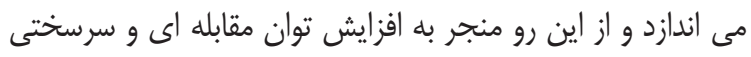

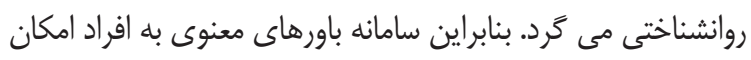

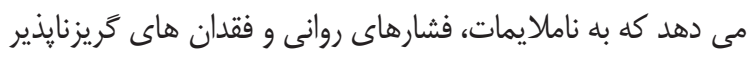

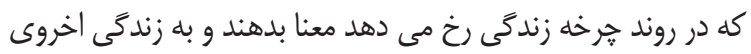

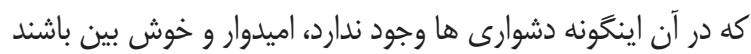

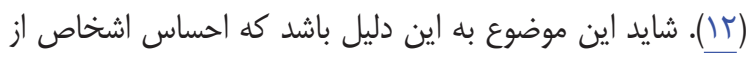

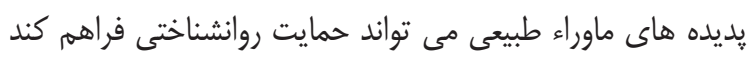

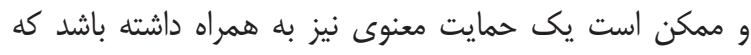

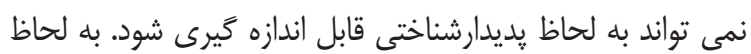

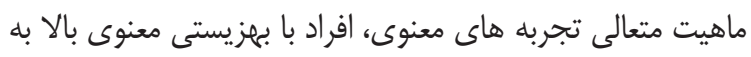

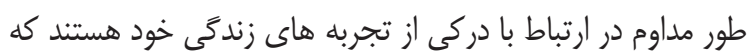

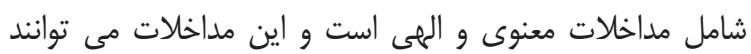

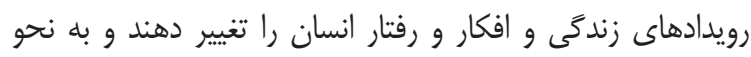

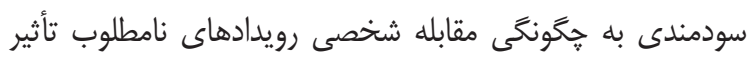

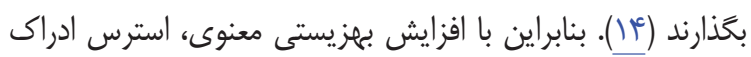
شده س سالمندان كاهش خواهد يافت.

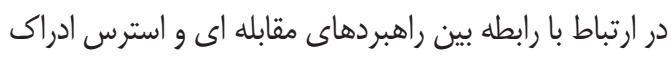
شده ى سالمندان، نتايج ضرايب همبستخى نشان داد نمره راهبرد

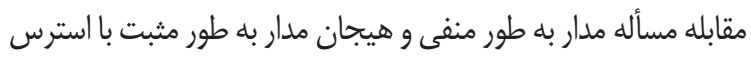
ادراك شده ى سالمندان مرتبط است. نتايج تحليل ركرسيون نيز

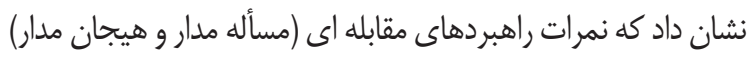
قدرت بيشبينى استرس ادراك شده ى سالمندان را دارند. بنابراين يافتهها از وجود ارتباط بين راهبردهاى مقابله اى با استرس ادراك

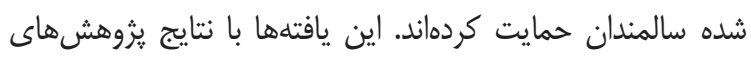

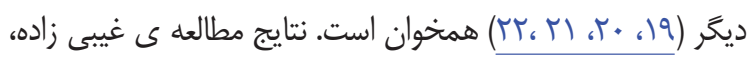
يورقانع، مصفا خمامى، حيدرى و عطر كارووشن (19) مؤيد اين نكته

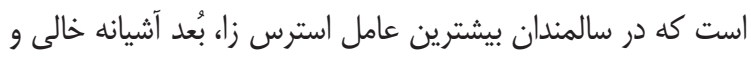
بيشترين راهبرد مقابله اى به كار رفته از سوى سالمندان، راهبرد

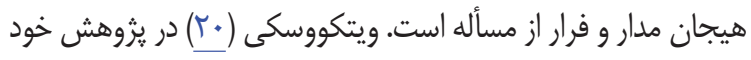

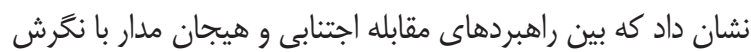


و مشاهده استفاده شود تا اطلاعات كامل تر و دقيق تر به دست آيد. همجنين با توجه به پايين بودن حجم جامعه در دسترس، خرده مقياسهاى متغيرها مورد مطالعه قرار نخَرفته و فقط اثر نمره كلى بررسى شد. ييشنهاد مىشود در مطالعات بعدى، نقش خرده مقياسهاى متغيرهاى ييش بين (بهزيستى معنوى، حس انسجام) در ييشبينى استرس ادراك شده مى سالمندان بررسى شود.

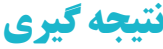

در مجموع مى توان كَفت كه بهزيستى معنوى، راهبردهاى مقابله اى و حس انسجام با استرس ادراك شده ى سالمندان رابطه داشته و مى تواند نحوه رفتار فرد در برابر استرس را بيش بينى كند. لذا آموزش سالمندان جهت توانمندسازى آنها در اين زمينه ها تها ييشنهاد مى شود.

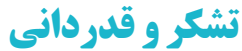

در پايان، نويسندكان اين مقاله از مديريت محترم دانشگًاه و

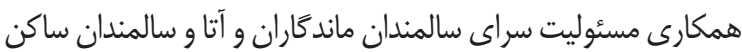
در آنجا كمال تشكر و قدردانى را به عمل مى آورند. اين مقاله برگر فته از كار يزوهشى مى باشد و هيج كَونه حمايت مالى از سوى سازمان يا

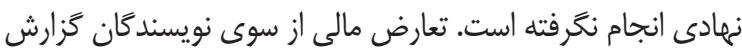

\section{Refrences}

1. United Nations, Department of Economic and Social Affairs, Population Division (2017). World Population Prospects: The 2017 Revision, Key Findings and Advance Tables. Working Paper No. ESA/P/WP/248.

2. Mirzaie M, Darabi S. Population aging in Iran and rising health care costs. Salmand: Iranian Journal of Ageing. 2017; 12 (2): 156 - 69.

3. Marengoni A, Angleman S, Melis R, Mangialasche F, Karp A, Garmen A, et al. Aging with multimorbidity: a systematic review of the literature. Ageing Research Reviews. 2011; 10 (4): 430 - 9 .

4. Scott SB, Jackson BR, Bergeman CS. What contributes to perceived stress in later life? A recursive partitioning approach. Psychology and Aging. 2011; 26 (4): 830 - 43.

5. Osmanovic - Thunstrom A, Mossello E, Akerstedt T, Fratiglioni L, Wang HX. Do levels
حس انسجام عامل مهمى در يبش بينى كيفيت زندگى سالمندان

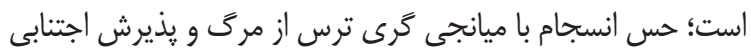

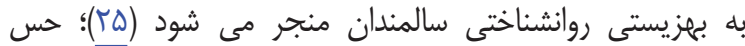
انسجام قوى با بهزيستى روانشناختى بيشتر در سالمندان همراه است (צr). براساس نظريه آنتونووسكى (سٓץ) قابليت درى حس انسجام دربردارنده مؤلفه هايى است كه حس شناخت را به وجود مى آورد. در افرادى كه حس انسجام بالا دارند، اطلاعات مربوط به مؤلفه هاى شناختى مرتب، جامع، ساختارمند و روشن بوده و مغشوش، آسيب

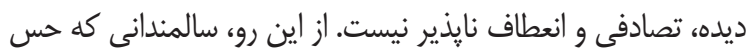
انسجام قوى در فهم مشكلات و رويدادهاى زندگى خود دارند، انتظار دارند محرك هاى مورد مواجهله أنها در آينده قابل ييش بينى باشند يا حداقل در زمان مواجهه ناگهانى با يك رويداد استرس زا، رفتارى مانى واضح و مرتبط از خود نشان دهند. همين مسأله باعث مى شود شدت خصايص بالينى استرس ادراك شده در آنها كاهش يابد.

يزروهش حاضر با محدوديت هايى نيز روبه رو بود. از جمله

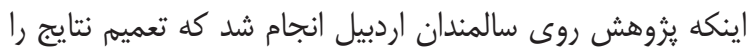
به ساير شهرستان ها با مشكل مواجه مى كند. از اين رو ييشنهاد مى شود يزوهشى مشابه اين يزوهش روى سالمندان در شهرهاى

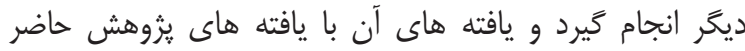

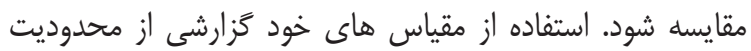
هاى ديخر اين ثروهش است. بنابراين ريشنهاد مى شود از روش هاى ديخر جمع آورى اطلاعات همجون مصاحبه (فردى، خانوادگى)

of perceived stress increase with increasing age after age 65? A population-based study. Age and Ageing. 2015; 44 (5): 828 - 34.

6. Peavy GM, Lange KL, Salmon DP, Patterson TL, Goldman S, Gamst AC, et al. The effects of prolonged stress and APOE genotype on memory and cortisol in older adults. Biological Psychiatry. 2007; 62 (5): 472 - 8.

7. Peavy GM, Jacobson MW, Salmon DP, Gamst AC, Patterson TL, Goldman S, et al. The influence of chronic stress on dementia-related diagnostic change in older adults. Alzheimers Disease \& Associated Disorders. 2013; 26: 2606.

8. Aldwin CM, Molitor NT, Avron S, Levenson, MR, Molitor J, Igarashi H. Do stress trajectories predict mortality in older men? Longitudinal findings from the VA normative aging study. Journal of Aging Research. 2011; 896109. 
9. Rekha P, Laxmi S. Spirituality and elderly. Journal of wellbeing. 2008; 1 (1): 34 - 8.

10. Scortegagna HDM, Pichler NA, Fáccio LF. The experience of spirituality among institutionalized elderly people. Revista Brasileira de Geriatria e Gerontologia. 2018; 21 (3): 432 - 41.

11. Solaimanizadeh F, Mohammadinia N, Solaimanizadeh L. The relationship between spiritual health and religious coping with death anxiety in the elderly. Journal of Religion and Health. 2019;

12. Kim SS, Kim-Godwin YS, Koeing HG. Family spirituality and family health among KoreanAmerican elderly couples. Journal of Religion and Health. 2016; 55: 729 - 46.

13. Seraji M, Shojaezade D, Rakhshani F. The relationship between spiritual well-being and quality of life among the elderly people residing in Zahedan city (South-East of Iran). Elderly Health Journal. 2016; 2 (2): 84-8.

14. Jafaripoor H, Safarabadi M, Pourandish Y, Khanmohammadi A, Mohammad Aghaiepoor S, Rahbarian A, et al. The elders' spiritual wellbeing and their quality of life: A cross-sectional Sstudy. Journal of Client-Centered Nursing Care. 2018; 4 (3):145 - 54.

15. Zimmer Z, Jagger C, Chiu CT, Ofstedal MB, Rojao F, Saito Y. Spirituality, religiosity, aging and health in global perspective: A review. SSM - Population Health. 2016; 2: 373 - 81.

16. Lee YH, Salman A. The mediating effect of spiritual well-being on depressive symptoms and health-related quality of life among elders. Archives of Psychiatric Nursing. 2018; 32 (3): 418-24.

17. Salman A, Lee YH. Spiritual practices and effects of spiritual well-being and depression on elders' self-perceived health. Applied Nursing Research. 2019; 48: 68 - 74.

18. Lazarus SR. Toward better research on stress and coping. American Psychologist. 2000; 55 (6): $665-73$.

19. Gheibizadeh M, Pourghane P, Mossaffa khomami H, Heidari F, Atrkar Roushan Z. Identifying the determinants of stress in the retired elderly. Journal of Geriatric Nursing. 2016; 3 (1):49 - 61.

20. Wittkowski J. Coping and attitudes toward dying and death in German adults. Journal of Death and Dying. 2015; 72 (4): 316 - 39.
21. Hashemi Razini H, Baheshmat Juybari S, Ramshini M. Relationship between coping strategies and locus of control with the anxiety of death in old people. Salmand: Iranian Journal of Ageing. 2017; 12 (2): 232 - 41.

22. Chen Y, Peng Y, Xu H, O'Brien WH. Age differences in stress and coping: Problemfocused strategies mediate the relationship between age and positive; affect. International Journal of Aging \& Human Development. 2018; 86 (4): 347 - 63.

23. Antonovsky A. The structure and properties of the sense of coherence scale. Social Science \& Medicine. 1993; 36 (6):725 - 33.

24. Taghavi S, Afshar PF, Bagheri T, Naderi N, Amin A, Khalili Y. The Relationship Between Spiritual Health and Quality of Life of Heart Transplant Candidates. Journal of Religion and Health. 2019 2019/11/19.

25. Nezamdoust Sedehi M, Borjali A, Poursharifi H, Kraskian Mujembari A, Seirafi M. The relationship between hope and sense of coherence with psychosocial well-being among older people: Mediating role of attitude toward death. Journal of Aging Psychology. 2018; 4 (3): $179-95$.

26. Nilsson KW, Leppert J, Simonsson B, Starrin B. Sense of coherence and psychological well-being: improvement with age. Journal of Epidemiology \& Community Health. 2010; 64 (4): 347 - 52.

27. Giglio RE, Rodriguez-Blazquez C, de PedroCuesta J, Forjaz MJ. Sense of coherence and health of community-dwelling older adults in Spain. International Psychogeriatrics. 2015; 27 (4): $621-8$.

28. Humboldt SV, Pimenta ILF. Sense of coherence, sociodemographic, lifestyle, and health-related factors in older adults' subjective well-being. International Journal of Gerontology. 2015; 9 (1):15 - 9 .

29. Boeckxstaens P, Vaes B, Sutter AD, Aujoulat I, Pottelbergh GV, Matheï, C, et al. A high sense of coherence as protection against adverse health outcomes in patients aged 80 years and older. Annals of Family Medicine. 2016; 14 (4): $337-$ 43.

30. Huang LJ, Du WT, Liu YC, Guo LN, Zhang JJ, Qin MM, et al. Loneliness, stress, and depressive 
symptoms among the Chinese rural empty nest elderly: A moderated mediation analysis. Journal Issues in Mental Health Nursing. 2019; 40 (1):73 $-8$.

31. Ronnlund M, Astrom E, Adolfsson R, Carelli MG. Perceived stress in adults aged 65 to 90 : Relations to facets of time Pperspective and COMT Val158Met Polymorphism. Frontiers in Psychology. 2018; 22 (9): 378.

32. Delaware AS. Research methodology in psychology and educational sciences. Tehran: Virayesh Pub; 2017.

33. Cohen S, Kamarck T, Mermelstein R. A global measure of perceived stress. Journal of Health and Social Behavior. 1983; 24 (4): 385 - 96.

34. Behroozi N, Shahani Yeylaq M, Pourseyed SM. Relationship between perfectionism, perceived stress and social support with academic burnout. Rahborde Farhang 2013; 5 (20): 83 - 102.

35. Paloutzian RF, Ellison CW. Loneliness, spiritual well- being, and quality of life. In L. A. Peplau, \& D. Perlman (Eds.), Loneliness: A Sourcebook foe current theory, research, and therapy. New York: Wiley Interscience; 1982.

36. Dehshiri Gh, Sohrabi F, Jafari E, Najafi M. Investigation of psychometric properties of spiritual well-being scale among students. Psychological Study. 2008; 4 (3): 35 - 45.

37. Lazarus RS, Folkman S. Transactional theory and research on emotions and coping. European Journal of Personality. 1987;1 (3):141 - 69.

38. Rajabi-Damavandi G, Pooshineh K, GhobariBonab B. Relationship between personality traits and coping strategies in parents with children with autism spectrum disorders. Research Except. 2009; 9 (2):133 - 44.

39. Rohani C, Khanjari S, Abedi HA, Oskouie F, Langius-Eklöf A. Health index, sense of coherence scale, brief religious coping scale and spiritual perspective scale: Psychometric properties. Journal of Advanced Nursing. 2010; 66 (12): 2796 - 806.

40. Lustig DC, Rosenthal DA, Strauser DR, Haynes $\mathrm{K}$. The relationship between sense of coherence and adjustment in persons with disabilities. Rehabilitation Counseling Bulletin. 2000; 43 (3):134 - 41 .

41. Mahammadzadeh A, Poursharifi H, Alipour A. Validation of sense of coherence (SOC) 13 - item scale in Iranian sample. Procedia Social and Behavioral Sciences. 2010; 5: 1451 - 5. 